INJURY CLASSIC

\title{
Tap water scald burns in children
}

\author{
Kenneth W Feldman, Robert T Schaller, Jane A Feldman, Mollie McMillon
}

This is the 17th paper in a series of Injury Classics.

Our goal is to reprint one or two such papers in each issue to introduce newcomers to these old, often quoted, and important contributions. As many are difficult to find, it should help all of us to have a copy at hand. Your suggestions about future articles are welcome. Write to the editor with details of your favourite, most quoted paper.

Odessa Brown Children's Clinic and Burn Unit of the Children's Orthopedic Hospital and Medical Center and the Ambulatory Division, Department of

Pediatrics, University of Washington School of Medicine, Seattle, USA

This paper first appeared in Pediatrics (1977;62:1-7) and is reproduced by permission.

\begin{abstract}
Tap water scald burns account for $7 \%$ to $17 \%$ of all childhood scald burns that require hospitalization. Often the burns are severe and disabling. Toddlers and preschool children are the most frequent victims. In $45 \%$ of the injuries, the unsupervised victim or a peer turned on the tap water; in $28 \%$ the cause was abuse. Eighty per cent of the homes tested had unsafe bathtub water temperatures of $54^{\circ} \mathrm{C}\left(130^{\circ} \mathrm{F}\right)$ or greater, exposing the occupants to the risk of full thickness scalds with 30 second exposure to hot water. Such burns may be prevented passively by limiting household water temperatures to less than $52^{\circ} \mathrm{C}\left(125^{\circ} \mathrm{F}\right)$. New water heaters could be preset at this temperature and families could be taught to turn down the temperature on existing units.
\end{abstract}

(Pediatrics 1977;62:1-7)

The most effective approaches to prevention of childhood accidents do not depend on the cooperation of the child or the person who is taking care of him. Recent examples of passive preventive techniques include flame resistant clothing and poison prevention packaging. Methods that require active effort (for example, automobile safety restraints) have also reduced injury, but their effectiveness is hampered by poor compliance.

Scald burns are the most common type of thermal injury in children ${ }^{12}$ and their prevention has been frustrated because of the need for active methods. Scald burns caused by hot tap water are a subgroup that has received little attention but that may be amenable to both active and passive modes of prevention. This study was undertaken to assess the magnitude of the problem and to determine the feasibility of preventive measures.

Charts of hospitalized scald burn victims and emergency surveillance data were analyzed to determine whether the characteristics of the victims and circumstances of their injuries suggested modes of prevention. Home water temperatures were surveyed to determine the frequency of exposure to dangerous water temperatures. Households were questioned about their knowledge of the risk of hot tap water, satisfaction with the quantity and temperature of their hot water, and past preventive efforts such as turning down the water heater thermo- stat. Pediatric health care professionals also were questioned about their knowledge of appropriate home water temperatures.

\section{Materials and methods}

EMERGENCY ROOM SURVEILLANCE

The computer data bank of the National Electronic Injury Surveillance System (NEISS) of the United States Consumer Product Safety Commission involves product related injuries. One hundred nineteen selected hospital emergency rooms that are statistically representative of emergency rooms in the United States are surveyed. The system was searched for all scald burns in 18 tap water related product categories and for all other scald burns in children through 14 years of age for the year 1975. Age, sex, severity, and national incidence figures were obtained.

INPATIENT CHART REVIEW

Summaries of all patients with scald burns who were admitted to the Children's Orthopedic Hospital and Medical Center (COHMC) from 1963 to 1976 and to the regional burn unit of the Harborview Medical Center (HMC) for 1975 and 1976 were reviewed. The charts of all patients who sustained tap water injury were examined in detail. (Scalds include all burns caused by contact with hot liquid; "other scalds" include all scalds caused by liquids other than hot water coming directly from the tap.) To obtain a random sample of other scalds for comparison, the records of all scalded patients hospitalized at COHMC and HMC with a chart number ending in 3 or 7 were examined in detail; this yielded 67 cases from a total of 318 .

HOME TAP WATER SURVEY

Fifty seven Seattle households were evaluated in a survey of home water temperatures. Of 62 homes visited in a consecutive door-to-door survey of a white, upper middle class neighborhood, 31 families were present and consented to be surveyed. Twenty six of 30 families chosen from the Woman, Infant, and Children Program list of a pediatric clinic serving primarily low income, black families consented to participate in the home survey conducted by the clinic's outreach worker. Neither sample was selected randomly. An adult from the household was interviewed to determine awareness of the risk of tap water scalds and past preventive methods. The water temperature in a bathtub was checked using a Reotemp 
Table 1 NEISS outpatient scald burns in patients 0 to 14 years old in 1975

\begin{tabular}{lll}
\hline & $\begin{array}{l}\text { Tap water } \\
\text { scalds } \\
\text { No }(\%)\end{array}$ & $\begin{array}{l}\text { Other scalds } \\
\text { No (\%) }\end{array}$ \\
\hline Severity grade & & \\
$\quad 0-5$ & $25(61.0)$ & $1393(85.9)$ \\
$\quad 6-7(>25 \%$ body surface area) & $16(39.0)$ & $230(14.2)^{\star}$ \\
Not hospitalized & $28(68.3)$ & $1460(90.0)$ \\
Hospitalized & $13(31.7)$ & $162(10.0) \dagger$ \\
Total & $41(100.0)$ & $1622(100.0)$ \\
${ }^{\star} \chi^{2}, \mathrm{p}<0.001$. & & \\
$\dagger \chi^{2}, \mathrm{p}<0.0005$. & & \\
\end{tabular}

Bimetal Thermometer (Reotemp Instrument Co, Van Nuys, Calif) at two minutes after turning on the water or when the water temperature stabilized, whichever occurred first. The water heater was checked to determine if it was adjustable.

PEDIATRIC PRACTITIONER SURVEY

A questionnaire was distributed to participants at a pediatric grand rounds at COHMC usually attended by about 100 primary care and hospital based pediatricians. They were asked what

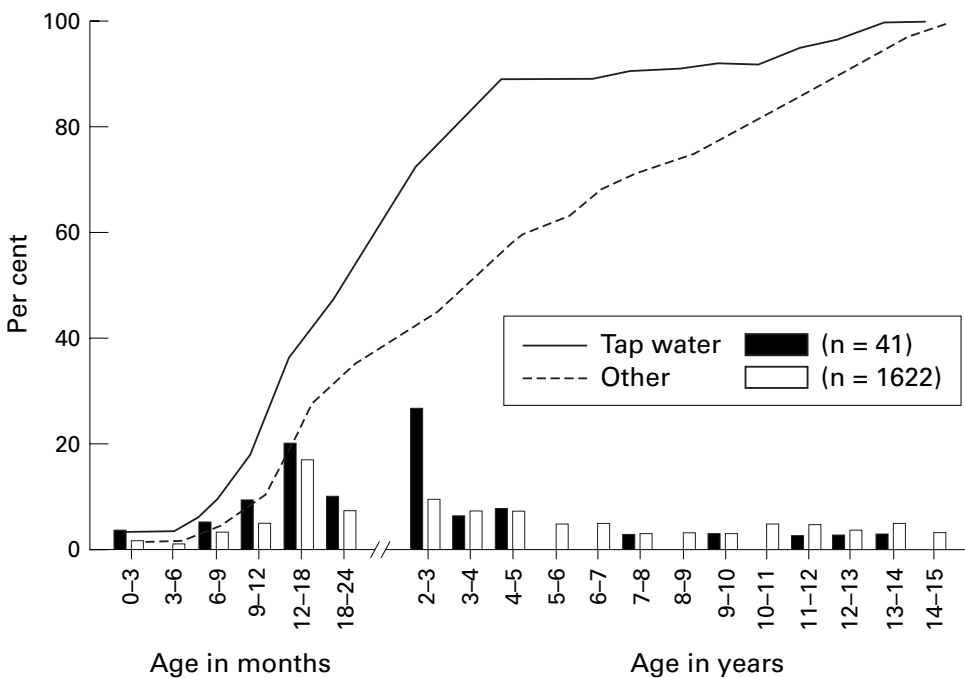

Figure 1 Age distribution by per cent and cumulative per cent of total for outpatient tap water scalds and other scalds reported to the NEISS in 1975.

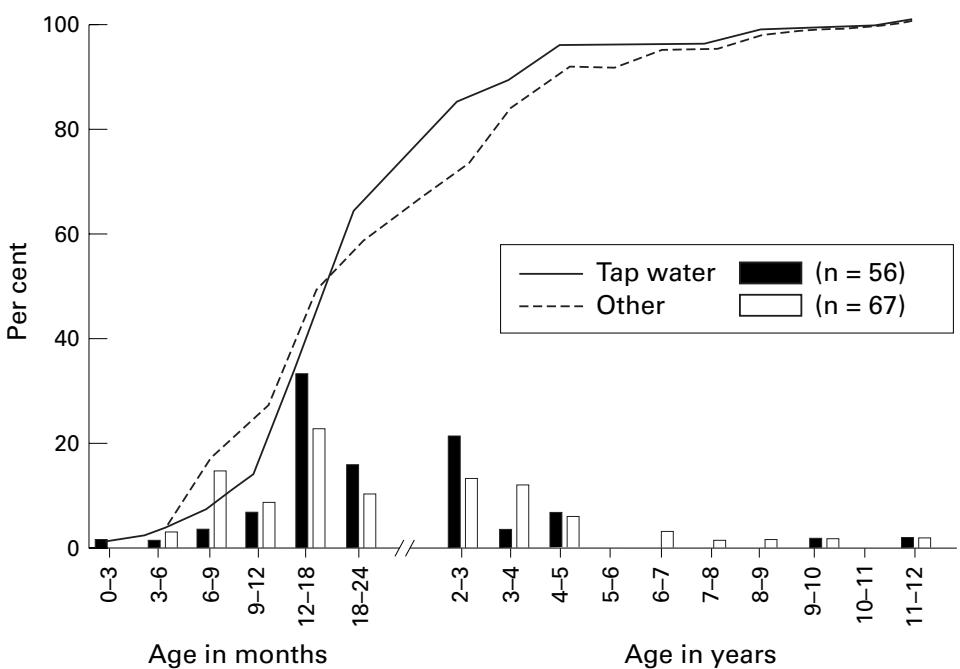

Figure 2 Age distribution by per cent and cumulative per cent of total for inpatient tap water scalds and other scaldsat Children's Orthopedic Hospital and Medical Center from 1963 to 1976 and the Harborview Medical Center during 1975 and 1976. the temperature setting of the water heater should be to prevent injury. Thirty two participants, including 13 pediatricians, responded. The other responses were from pediatric house staff, medical students, and nurses.

\section{STATISTICAL METHODS}

The economic class of the inpatient and home samples was determined from the principal household occupation according to Hollingshead's classification (A B Hollingshead, unpublished data, 1956). Educational data were not available. Significance was determined using the $\chi^{2}$ test for $2 \times 2\left(\chi_{1}^{2}\right)$ and $2 \times \kappa\left(\chi_{k-1}^{2}\right)$ contingency tables, Student's two sample $t$ test, Wilcoxon rank sum $\left(T_{1}\right)$ with normal approximation, and Spearman's rank correlation $\left(r_{s}\right)$ where appropriate. The values expressed are means \pm 2 SDs and probabilities greater than 0.05 are expressed as not significant (NS).

\section{Results}

EMERGENCY ROOM SURVEILLANCE

Based on reports of 89 tap water scalds in 1975, NEISS extrapolates that 2473 tap water scalds were seen that year in emergency rooms nationally; $543(22.0 \%)$ involved children less than 15 years of age. The tap water scalds reported to NEISS were more extensive than other scalds and were more likely to result in hospitalization (L G Desbordes, personal communication) (table 1). Thirty nine per cent of the tap water scalds involved $25 \%$ or greater body surface area and 32\% required hospitalization. No final outcome data such as mortality are available for this sample. Scalds of all types were most frequent in toddlers and preschool children; in the older children other scalds were more common. Eighty eight per cent of all tap water scalds, but only $60 \%$ of other scalds, had occurred by age 5 (fig 1 ).

\section{INPATIENT CHART REVIEW}

An average of 3.6 patients with tap water scalds and 19.4 with other scalds were hospitalized annually at COHMC from 1963 to 1976 . The incidence of both types of scalds during this time period has been constant. An additional 2.5 patients with tap water scalds and 23 with other scalds were hospitalized annually at HMC during 1975 and 1976. Since the geographic areas for these institutions are large and varied, the incidence of scald burns requiring emergency room care only could not be determined. The age distribution of hospitalized patients with tap water and other scalds is similar (fig 2) and the median age for both groups is 19 months. Sex, race, and economic class were also similar.

Tap water scalds tended to be more extensive than other scalds, involving approximately twice the mean body surface area; $12.5 \%$ of tap water scalds, but only $1.5 \%$ of other scalds, involved $40 \%$ or more body surface area. This difference is reflected in a mortality of $12.5 \%$ among the tap water scald victims and $0.3 \%$ for those with other scalds. With tap water scalds, the body part scalded was usually the presenting part. If a child was placed in a tub of drawn 
Table 2 Severity of inpatient scalds at Children's Orthopedic Hospital and Harborview Medical Center

\begin{tabular}{llll}
\hline & $\begin{array}{c}\text { Tap water scalds } \\
\text { No (\%) }\end{array}$ & $\begin{array}{l}\text { Other scalds } \\
\text { No (\%) }\end{array}$ & $\begin{array}{l}\text { Significance } \\
\text { level }\end{array}$ \\
\hline Total patients & $56(100.0)$ & $67(100.0)$ & \\
$\begin{array}{l}\text { Per cent body surface area 2nd and 3rd degree scald } \\
\quad \text { Mean }\end{array}$ & $19.4 \pm 33.0$ & $10.6 \pm 17.6$ & $\mathrm{p}<0.0002$ \\
$\quad$ Median & 12 & 9 & \\
Grafted & $16(28.6)$ & $16(23.9)$ & $\mathrm{NS}^{\star}$ \\
Contracture & $10(17.9)$ & $6(9.0)$ & $\mathrm{NS}$ \\
Hypertrophic scar & $16(28.6)$ & $16(23.9)$ & $\mathrm{NS}$ \\
Died & $7(12.5)$ & $0(0.0) \dagger$ & $\mathrm{p}<0.001$ \\
Duration in hospital (days) & & & \\
$\quad$ Mean & $21.4 \pm 39.8$ & $13.9 \pm 25.4$ & $\mathrm{p}<0.001$ \\
$\quad$ Median & 17 & 9 &
\end{tabular}

${ }^{\star} \mathrm{NS}=\mathrm{p}>0.05$.

†No deaths occurred in the 67 patients with other scalds examined in detail, but one death occurred in the entire population of 318 other scalds.

Table 3 Abuse in inpatient scalds

\begin{tabular}{|c|c|c|}
\hline & \multicolumn{2}{|l|}{ Incidence } \\
\hline & $\begin{array}{l}\text { Tap water scalds } \\
\text { No }(\%)\end{array}$ & $\begin{array}{l}\text { Other scalds } \\
\text { No }(\%)\end{array}$ \\
\hline "Stress" & $21(37.5)$ & $13(19.4)^{\star}$ \\
\hline Abuse & $6(10.7)$ & $1(1.5)$ \\
\hline Suspected abuse & $10(17.9)$ & $3(4.5)$ \\
\hline Total abuse & $16(28.6)$ & $4(6.0)^{\star}$ \\
\hline Total & $56(100.0)$ & $67(100.0)$ \\
\hline \multicolumn{3}{|l|}{ Associations } \\
\hline Abused males/total males & & $11 / 30(36.7 \%)$ \\
\hline Abused females/total females & & $5 / 26(19.3 \%)$ \\
\hline Abuse-adult in the same room as the victim & & $10 / 21(47.6 \%)$ \\
\hline Abuse-adult in other room than the victim & & $6 / 23(26.1 \%)$ \\
\hline \multicolumn{3}{|c|}{ Abuse-person other than attendant at time of injury took victim for medical care } \\
\hline Tap water & & $5 / 7(71.4 \%)$ \\
\hline Other scald & & 4/7 (57.1\%) \\
\hline Abuse-adult drew the tap water & & $12 / 20(60.0 \%)$ \\
\hline Abuse-scald seen promptly & & $9 / 41(21.9 \%)$ \\
\hline Abuse-delay in seeking care $>2$ hours & & $7 / 10(70.0 \%)$ \\
\hline
\end{tabular}

hot water, buttocks, legs, and hands were usually involved. If the injury occurred under running water, buttocks, feet, or shoulders were scaled. "Stocking" and "splash" injuries were common. Scarring involved normally clothed parts of the body, and feet were the usual site of joint contracture. Grafting, hypertrophic scar, and joint contracture were common in all scalds (table 2).

Abuse was diagnosed in six cases and strongly suspected in 10 . The 10 cases were classified as abuse in the analysis (table 3 ). Abuse was twice as frequent in boys and was more likely when an adult was in the same room with the victim and when the victim was brought for medical care by someone other than the attendant at the time of injury. When medical care was delayed more than two hours, the injury was more likely to be abusive (table 3). Abuse was not correlated with the extent of injury.

The patients' physicians commented frequently on major family disruption such as

Table 4 Stress and abuse versus occupational class in inpatient scald burns

\begin{tabular}{lll}
\hline Occupational class $^{*}$ & Stress & Abuse \\
\hline $1-4$ & $4 / 13(30.8 \%)$ & $0 / 13(0.0 \%)$ \\
5 & $2 / 10(20.0 \%)$ & $2 / 10(20.0 \%)$ \\
6 & $5 / 10(50.0 \%)$ & $3 / 10(30.0 \%)$ \\
7 & $16 / 23(69.6 \%)$ & $11 / 23(47.8 \%)$ \\
Total & $27 / 56(37.5 \%)$ & $16 / 56(28.6 \%)$ \\
$\chi^{2}{ }_{3}$ & $\mathrm{p}<0.05$ & $\mathrm{p}<0.025$ \\
\hline
\end{tabular}

^From A B Hollingshead, unpublished data, 1956. chronic neglect, parent in jail, or divorce in progress. These situations have been grouped in a non-specific category called "stress". Since these comments were not sought prospectively with preselected criteria, recognition depended on the efforts of those administering care to seek and record such events. Many stressed families may not have been identified. Stress, injury, and abuse were all more frequent in the lower economic classes (table 4).

In $45 \%$ of the tap water scalds the victim or a peer turned on the water, whereas in $78 \%$ of the other scalds a child initiated the injury. Of the tap water scalds in which an adult turned on the water, $60 \%$ were abusive.

Tap water burns usually occurred in the bathtub or shower $(74 \%)$ or sink $(22 \%)$. Coffee, tea, and other foods accounted for $97 \%$ of other scalds.

\section{CASE HISTORIES}

Case 29

All 11 month old boy was the unplanned third child of a Korean war bride. After being delivered spontaneously in a toilet bowl at 32 weeks' gestation, he was hospitalized for 40 days with idiopathic respiratory distress syndrome. His mother made several suicide attempts after his birth. The boy's burn occurred when his mother placed him in a portable plastic tub and turned on only the hot water. His father returned home $51 / 2$ hours after the injury and took him to receive medical care. The child sustained $35 \%$ second and third degree burns involving the lower half of his body. A skull fracture was also noted. Grafting was required twice, resulting in joint contracture and hypertrophic scarring of the legs. He was hospitalized for 73 days and discharged to the care of his father's parents.

\section{Case 26}

A 23 month old white girl who was left unattended in the bathtub turned on the hot water. Her father was away in the army and her mother was receiving welfare assistance. Hygiene in the home was described as extremely poor. The child suffered a 35\% second degree burn involving both legs from the thighs down. She was hospitalized for 23 days.

\section{Case 25}

When a 28 month old girl soiled her diapers, her father, an unemployed logger who was receiving welfare assistance, held her buttocks under the faucet of the bathroom sink to rinse her. Although he thought he turned on both hot and cold taps, only the hot was running. The child received a $12 \%$ first and second degree burn of the buttocks, perineum, and left thigh. She was hospitalized for 19 days. There were no residual problems.

Case 21

An 11 month old white boy playing in the bathtub fell and grasped the hot water handle. He was discovered by his parents "in a few seconds" after sustaining 30\% first and second degree burns of the lower part of the back, 


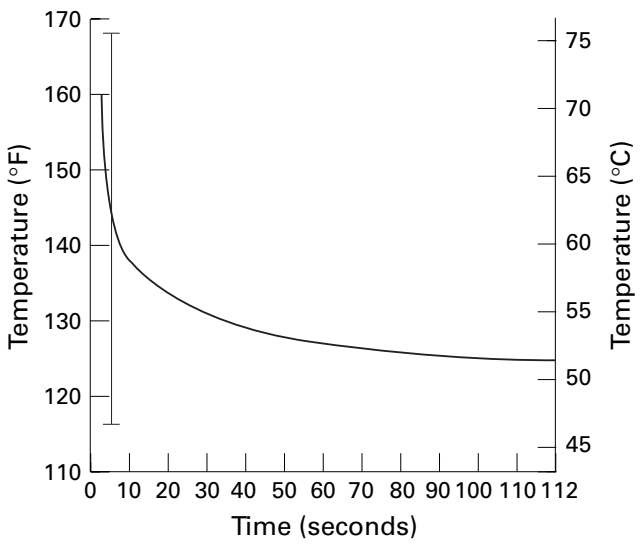

Figure 3 Mean home bathtub water temperature ( $\pm 2 S D$ ) plotted on a curve of duration of exposure to hot water required to cause full thickness scalds of adult skin at various water temperatures. Adapted from Mortiz and Henriques. $^{3}$

flanks, buttocks, and left thigh. $\mathrm{He}$ was hospitalized for 11 days. No residual problems occurred.

Case 14

The mother (a nurse) of a 17 month old white boy had turned up the temperature of the family's water heater because it was "so inefficient". The infant, while sitting beside the kitchen sink as his mother warmed his bottle under running water, fell into the sink and sustained $14 \%$ first and second degree burns of his neck and shoulders. He was hospitalized for six days. There were no residual problems.

Case 47

The 5 year old sibling of a 17 month old white boy was being "mother's helper" by putting the toddler in the bathtub. The 5 year old turned on the hot water. The toddler received $20 \%$ second degree and 5\% third degree burns of the forearms, entire right left, and lower left leg. He was hospitalized for 26 days. Grafting and surgical release of scar contracture were required.

HOME TAP WATER SURVEY

The mean home bathtub water temperature of 57 homes tested was $61 \pm 14^{\circ} \mathrm{C}\left(142 \pm 26^{\circ} \mathrm{F}\right)$ with a range of 32 to $76^{\circ} \mathrm{C}$ (90 to $168^{\circ} \mathrm{F}$ ) (fig 3 ). Eighty per cent of the homes visited had bathtub water temperatures greater than $54^{\circ} \mathrm{C}$ $\left(130^{\circ} \mathrm{F}\right)$, which exposes the occupants to the risk of full thickness scald burns with exposures of 30 seconds. $^{3}$ There was no correlation of water temperature with economic class, neighborhood sampled, previous efforts to adjust the water temperature, acquaintance with previous victims of tap water scalds, children less than 5 years old in the home, or the expectation that tap water scalds would be a common problem. There was no significant difference in water temperature in homes with electric or gas water heaters. Likewise, there was no correlation of water temperature with those families who were or were not satisfied with the amount or temperature of their hot water.

Families were usually unaware that tap water could be hazardous and did not know what water temperatures could cause burns. When asked the temperature required to cause a scald with a one minute and a one second exposure to hot water, 22 of the 57 people asked answered $59 \pm 33^{\circ} \mathrm{C}\left(138 \pm 59^{\circ} \mathrm{F}\right)$ and 29 people answered $66 \pm 45^{\circ} \mathrm{C}\left(151 \pm 81^{\circ} \mathrm{F}\right)$, ranges of 38 to $100^{\circ} \mathrm{C}\left(100\right.$ to $\left.212^{\circ} \mathrm{F}\right)$, respectively. The correct answers are $53^{\circ} \mathrm{C}\left(127^{\circ} \mathrm{F}\right)$ and $70^{\circ} \mathrm{C}$ $\left(158^{\circ} \mathrm{F}\right) .^{3}$

Of the 51 families who had control of their water heaters, 45 thought that they were adjustable but only 23 had attempted to adjust them. All heaters examined were adjustable. The temperatures of the heaters that were adjusted by the service corps of the local power company were usually 60 to $66^{\circ} \mathrm{C}$ (140 to $\left.150^{\circ} \mathrm{F}\right)$, and the heater with the highest temperature, $76^{\circ} \mathrm{C}\left(168^{\circ} \mathrm{F}\right)$, had been checked by them.

PEDIATRIC PRACTITIONER SURVEY

Twelve of 32 participants $(37.5 \%)$ in the pediatric grand rounds replied that they would recommend home water temperatures greater than $54^{\circ} \mathrm{C}\left(130^{\circ} \mathrm{F}\right)$; answers ranged from 41 to $74^{\circ} \mathrm{C}\left(105\right.$ to $\left.165^{\circ} \mathrm{F}\right)$.

\section{Discussion}

In the context of the more frequent food scalds and flame burns, tap water scalds may seem to be an infrequent and insignificant problem. However, tap water injuries have accounted for $14.3 \%^{1}$ and $16.9 \%^{2}$ of hospitalized patients with scald burns in previous studies. Tap water caused $7.4 \%$ of the hospitalizations in the 1975 NEISS scald burn sample and $14.9 \%$ of the current inpatient scald burn population. If hospitalization was required, the tap water burns resulted in greater mortality and morbidity than other scalds. Since 1971, a total of 44 patients have been hospitalized at Brooke Army Hospital, with a mortality of $34 \%{ }^{4}$

Tap water and other scalds are most frequent at the toddler and preschool ages when curiosity, mimicry, or abuse cause a child to get into hot water that he cannot escape. The two oldest members of the inpatient tap water series (a 9 year old child with severe cerebral palsy and a 12 year old child with hemiplegia and hemophilia) are typical of the adult pattern of tap water scalds in which neurologic, motor, or psychiatric disability predispose to injury. ${ }^{5}$

Tap water scalds have been noted to be a mode of child abuse..$^{6-8}$ The $28 \%$ incidence of abuse in the current study confirms this observation.

Since water temperature did not vary with economic class, other causes must exist for the greater frequency of injury in the lower economic classes.

In $45 \%$ of the tap water injuries, the victim or a peer turned on the water. Either the water temperature has to be low enough to preclude injury or the person who takes care of the child has to be constantly vigilant to prevent such injury. In cases in which an adult turned on the water, $60 \%$ of the injuries were abusive. In the remainder, the adult was careless in checking the water temperature; and either he placed the 
victim in the water or the victim fell or jumped in. Education is not likely to prevent human error or the anger responsible for these two modes of injury, but decreased tap water temperature would.

Most of the injuries occurred in the bathtub or shower. The Consumer Product Safety Commission and the plumbing industry have proposed a voluntary standard requiring devices that limit tale temperature to $49^{\circ} \mathrm{C}$ $\left(120^{\circ} \mathrm{F}\right)$ on new bathtubs and showers. ${ }^{9}$ This standard would be effective in eliminating injury in such new installations, but the $26 \%$ of the injuries that occur in sinks or portable tubs would continue and existing plumbing would be unaffected. Water temperature control throughout the house would prevent these injuries. A water temperature of 49 to $52^{\circ} \mathrm{C}$ $\left(120\right.$ to $\left.125^{\circ} \mathrm{F}\right)$ is a reasonable compromise between a household's need for volume of hot water and safety.

At $49^{\circ} \mathrm{C}\left(120^{\circ} \mathrm{F}\right)$ it takes 10 minutes and at $52^{\circ} \mathrm{C}\left(125^{\circ} \mathrm{F}\right)$ it takes two minutes to cause full thickness burns of adult skin. ${ }^{3} \mathrm{~A}$ child's skin burns in less time. Home washing machines function well at these temperatures ${ }^{10}$ and it is too painful to wash dishes by hand in hotter water. Although intake temperatures of $60^{\circ} \mathrm{C}$ $\left(140^{\circ} \mathrm{F}\right)$ or greater are generally recommended for home dishwashers, commercial dishwasher detergent (Cascade) will adequately dissolve and sanitize at temperatures of $54^{\circ} \mathrm{C}\left(130^{\circ} \mathrm{F}\right)(\mathrm{J}$ $\mathrm{H}$ Benedict and E A Bannan, personal communication).

Currently, gas water heaters are preset at $60^{\circ} \mathrm{C}\left(140^{\circ} \mathrm{F}\right)^{11}$ (six seconds for a full thickness scald of adult skin) $)^{3}$ and electric heaters at $66^{\circ} \mathrm{C} \quad\left(150^{\circ} \mathrm{F}\right)^{11}$ (two seconds for a full thickness scald). ${ }^{3}$ The power companies in the Seattle area recommend water temperatures of 60 to $66^{\circ} \mathrm{C}\left(140\right.$ to $\left.150^{\circ} \mathrm{F}\right)$ and their service corps sets temperatures in this range. If manufacturers preset heaters at $52^{\circ} \mathrm{C}\left(125^{\circ} \mathrm{F}\right)$ and provide clear warning labels about the risk of higher temperatures, the incidence of scalds should be reduced.

Since the Federal Energy Administration estimates that the average life of a water heater is 10 years, ${ }^{11}$ about 10 years would be required to complete a water temperature changeover. In the meantime, private health care providers, fire departments, power companies, and the news media could provide information about the existing risk and recommend water temperature reduction. The current level of knowledge of pediatric health care providers about tap water injuries seems inadequate to provide meaningful safety counseling. Those who could provide safety counseling need to be aware of the risks of hot tap water. Since a $4 \%$ energy saving occurs with each $6^{\circ} \mathrm{C}\left(10^{\circ} \mathrm{F}\right)$ temperature reduction from $66^{\circ} \mathrm{C}\left(150^{\circ} \mathrm{F}\right)$, an additional incentive for lower water temperatures exists. ${ }^{11}$

The families interviewed were generally unaware of the risk of tap water scalds. When the problem was explained, most families were interested and several requested help in lowering the temperature of their water heater.

Gas heaters usually have a thermostat at the bottom, outside of the tank; the low setting corresponds to $49^{\circ} \mathrm{C}\left(120^{\circ} \mathrm{F}\right)$. Electric water heaters have either two panels screwed onto the top and bottom front of the tank or a single panel spanning the height of the tank. Beneath these panels and covered by insulation are two thermostats. Both should be set at $52^{\circ} \mathrm{C}$ $\left(125^{\circ} \mathrm{F}\right)$ or "low". Some households with small water heaters or a heavy use of hot water may feel that they run out of hot water too often and thus turn the temperature back up. In the current sample, satisfaction with the temperature and amount of hot water was not related to the actual water temperature. Perhaps those who do turn up the temperature will do so with a greater knowledge of the risk and with greater vigilance.

We are indebted to Drs Abraham B Bergman and Edgar K Marcuse for editorial comment; to the National Injury Information Clearinghouse, Bureau of Epidemiology, US Consumer Product Safety Commission; and to the Burn Unit of the Harborview Medical Center, Seattle. We thank Cheryl Herndon for illustrations and Barbara Robinson arid Cecilia Amado for typing.

1 Jensen GD. Preventive implications of a study of 100 children treated for serious burns. Pediatrics 1959;24:623. Smith EI. The epidemiology of burns: the cause and control of burns in children. Pediatrics 1969;44:821.

3 Moritz AR, Henriques FC. Studies of thermal injury: the relative importance of time and surface temperature in the relative importance of time and surface temperature in the
causation of cutaneous burns. Am F Pathol 1947;23:695.

4 Kaplan JZ, Mason AD. Hot tap water: a significant but Kaplan JZ, Mason AD. Hot tap water: a significant but
unappreciated problem. Abstract 13. Proceedings of the Ninth Annual Meeting of the American Burn Association. Ninth Annual Meeting of the

5 Stone RF, Blackwell DJ, Burton DJ. A systematic program to reduce the incidence of severity of bathtub and shower area injuries. Draft of the final report for the US Consumer Product Safety Commission, Cambridge, Mass, 1975.

6 Smith SM, Hanson R. 134 battered children: a medical and psychological study. BMF 1974;iii:666.

7 Stone NH, Rinaldo L, Humphry CR, et al. Child abuse by burning. Surg Clin North Am 1970;50:1419.

8 Keen JH, Lendrum J, Wolman B. Inflicted burns and scalds in children. $B M \mathcal{F}$ 1975;iv: 268 .

9 Product Safety and Liability Reporter 1976;4:743.

10 Consumers Institute News 1975;22:1.

11 Walsh B. Technical background information for appliance efficiency, targets of water heaters. Draft report for the Federal efficiency, targets of water heaters. Draft report for the
Energy Administration, Washington, DC, 1976. 